\title{
Influence By Injection Drug Use In Patients With Hiv-Tb
}

\author{
Nurul Syahida Abdul Rahman ${ }^{1}$ and Wan Muhamad Amir W Ahmad ${ }^{2}$ \\ ${ }^{1}$ (Department of Mathematics, Faculty of Science and Technology, Malaysia, Universiti Malaysia Terengganu \\ (UMT), 21030 Kuala Terengganu, Terengganu Malaysia) \\ ${ }^{2}$ (Department of Mathematics, Faculty of Science and Technology, Malaysia, Universiti Malaysia Terengganu \\ (UMT), 21030 Kuala Terengganu, Terengganu Malaysia)
}

\begin{abstract}
Every year reported a patient with HIV is increasing. HIV can infect humans, through sexual whether heterosexual or homosexual, infection through contaminated blood flow, such as sharing drug injection equipment and infection from mother to child. HIV / AIDS, TB and injection drug use (IDU) contribute to the spread of the epidemic and increased mortality rates in communities around the world. TB is the leading cause of death among HIV-infected IDUs. In this present paper, we present the results that gained from binary logistic regression method and used to model the relationship between the ordinal outcome variable. The significant variables are chosen based on the p-value criteria which associated with the significant level of model that lies at the level of $\alpha=0.25$. Logit determination and the correlation between the variables are also discussed for further analysis. The use of mathematical software PASWand AMOS version 18 is applied in this research as an alternative calculation procedure derived from the methodology. Among the factors involved in this study were age, gender, race, level of CD4 content of less than 200/mm3, heterosexual, receiving blood infected with HIV, smoking, hepatitis, pneumonia and toxoplasmosis. This study found that there were six significant factors were age, gender, levels of CD4 less than 200/mm3, heterosexual, smoking and pneumonia. For structural equation modeling showed that the critical ratio for the diagnosis of HIV and TB patient through HIV_TB: IDU and CD4 was significant level at 0.05 and have a strong relationship. Overall, the results showed that age, gender, level of CD4 content of less than $200 / \mathrm{mm}^{3}$, heterosexual, smoking and pneumonia were contributing factors to TB infection in people with HIV-positive through injection drug use (IDU) in Kelantan. The government and relevant parties should provide ongoing effort to increase awareness about the dangers of social relations and illness with TB and HIV-positive IDUs by conducting campaigns, talks and tighten laws involving social problems.
\end{abstract}

Keywords: HIV, TB, IDU, Logistic Regression Method and Structural Equation Modeling

\section{Introduction}

The case of HIV is increasingly reported. HIV can infect humans, through sexual whether heterosexual or homosexual, infection through contaminated blood flow, such as sharing drug injection equipment and infection from mother to child. HIV / AIDS, TB and injection drug use (IDU) contribute to the spread of the epidemic and increased mortality rates in communities around the world. In Eastern Europe, China, Russia and Southeast Asia, IDU are the main method of transmission of HIV. TB is the leading cause of death among HIVinfected factors that can contribute to an individual beinginfected with HIV.Among the identified factors are smoking [10], blood transfusions [6], age [2], sex [8], CD4 cells [16], the sharing of contaminated drug injection needles and homosexual or heterosexual [7].

In Amsterdam half of all AIDS cases and a quarter of all TB cases diagnosed positive. A total of 6000 people are a group of addicts associated with an increased risk of TB disease before the HIV epidemic. Around 2500 the use of the drug injection needle in Amsterdam, and some 30\% are infected with HIV who live in other cities that describes the relationship between HIV and TB are the most obvious. HIV infection and active TB has been proven that this is brought about by the use of needle drug use (IDU) in Amsterdam [9]. Although not widely reported TB disease in Spain but studies show that the incidence of TB reported 30 times more common among those aged 15-45 years in prison Spain than among those aged equal in society. Centers for Disease Control (CDC) and the National Consensus Conference for the Control of Tuberculosis in Spain has shown that prison plays an important role in the prevention and control of TB. However, some of those who left the anti-TB treatment, particularly among IVDU which is a major problem. This is the main cause of TB disease are not effective against anti-TB drugs and growing problem in the United States and around the world [12].

\section{Literature Review}

Retrospective study conducted by Nissapatorn et al., 2003 [15] in reviewing 419 patients with HIV / AIDS at the Kuala Lumpur Hospital compact 1994 to 2001. Patients were divided into two parts, male and 
female. In the male group, the age range studied was between 20 to 74 years, with the average age is 37 yearsand while in the group of women is between 17 years to 63 years, with an average age of 33 years.

With regard to age groups, it wasfound that the predominant age group is between 25 years to 34 years. The majority of sufferers are a Chinese male (52.5\%), single (56.3\%), and Unemployment $(55.1 \%)$, while women are predominantly Malays (42.3\%), married (79.5\%), and unemployed (64.1\%). For both these groups, too, the main cause of HIV infection is heterosexual identified. While more than half of patients had a CD4 cell count less than 200 cells $/ \mathrm{mm}^{3}$. The results of this research also found that HIV infection through intravenous drug users (IDU) is directly related to the incidence of TB infection. The detailed analysis carried out revealed that the IDU HIV-related TB is also associated with employment status (unemployed). Four major diseases including tuberculosis AIDS (48\%), Pneumocystis carinii pneumonia (13\%), toxoplasmic encephalitis (11\%), and cryptococcal meningitis (7\%). In addition, 53\% of patients were found to have CD4 cells less than 200 cells $/ \mathrm{mm}^{3}$ during the diagnosis. Brassard et al., 2004 [5] through research stated that injection drug users (IDUs) at risk of developing active TB if they have latent TB infection (LTBI), regardless of their HIV status. Taking into account the IDU population in Montreal, participants monitored from time to time on an ongoing basis from the IDU group, followed by the risk of HIV infection. Subject to the tuberculin skin test (TST) mm were referred to the TB clinic set for medical evaluation. A total of 262 participants were tested, 246 (94\%) returned to TST reading. The overall prevalence of positive TST was $22 \%$ (5\% in HIV-positive, $28 \%$ HIV-negative participants). Older age at injection drug users (OR per 10-year increase of 1.4, 95\% CI 1.2-1.8), duration of injection drug use (OR per 10-year increase of 1.6, 95\% CI 1.5-2.2) and negative HIV status (OR 11.2, 95\% CI 3.2-4.0) were independent predictive positive TST.

\section{Study Area}

\section{Material And Methods}

This research was conducted in Kuala Terengganu. Kuala Terengganu is the capital of the Malaysian state of Negeri Terengganu.

\section{Study Population}

In this study, we calculate the sample size with manual calculation, with the significance level $(\alpha) 0.05$ and the confident intervel $95 \%\left(Z_{\alpha / 2}=1.96\right)$. The single Proportions formula is given as follows:

where:

$$
\text { Sample Size, } n=\left(\frac{z}{\Delta}\right)^{2} p(1-p)
$$

Sample Size $=n$

Significant level, $\alpha=0.05$

Absolute Precision $(\Delta)=5 \%$

Confident Interval $95 \%\left(Z_{\alpha / 2}=1.96\right)$

$P=$ Expected proportion of individuals in the sample with the characteristic of interest at the $100(1-\alpha) \%$ confidence interval. Anticipated population proportion $(p)=3 \%[17]$.

$$
\text { Sample Size, } n=\left(\frac{1.96}{0.05}\right)^{2} 0.03(1-0.03)
$$

Sample Size, $n=45$ patients

After adding $20 \%$ estimated missing data, we get $\mathrm{n}=45+(0.2 \times 45)=54$ per group, which can be obtained as follows:

$$
\begin{aligned}
& \text { i. Patients with IDU among HIV with TB } \\
& =54 \text { patients } \\
& \text { ii. Patients without IDU among HIV with TB } \\
& =54 \text { patients }
\end{aligned}
$$

Therefore, a total patient to be sampled is $(54 \times 2)=108$ patients. 
Table 1: Variable Description and Coding

\begin{tabular}{ll}
\hline Variable Name & Variable Description and Coding \\
\hline 1. Age & Age patient in years \\
2. Gender & Patient gender $($ female $=0$, male $=1)$ \\
3. Race & (non malay $=0$, malay $=1)$ \\
4. CD4 & Lessthan200 $/ \mathrm{mm} 3($ no $=0$, yes $=1)$ \\
5. Heterosexual & $($ no $=0$, yes $=1)$ \\
6. Receivingblood & $($ no $=0$, yes $=1)$ \\
7. Smoking & $($ no $=0$, yes $=1)$ \\
8. Hepatitis & $($ no $=0$, yes $=1)$ \\
9. Pneumonia & $($ no $=0$, yes $=1)$ \\
10. Toxoplasmosis & $($ no $=0$, yes $=1)$ \\
11. HIV_TB (IDU) & $($ no $=0$, yes $=1)$ \\
\hline
\end{tabular}

\section{Statistical Analysis}

Binary logistic regression analysis was conducted with reporting of odds ratio to establish HIV-positive incidentTBdiseaseamongIDUs (HIV_TB (IDU)). To explore the underlying association between HIV_TB (IDU) and the selected explanatory variables, a set of logistic regression models is fitted in this section. Let define the following dichotomous variables for the HIV_TB (IDU). Data were tabulated, cross tabulated and analyzed statistically using PASW version 18 . A probability value of $p<0.25$ was considered to be significant based on Mickey and Greenland (1989) [14]. They recommend the alpha was set to 0.25 levels and be used as a screening criterion for variable selection in logistic regression.

\section{Results}

To explore the underlying association between HIV_TB (IDU) and the selection explanatory variables, a set of logistic regression models is fitted in this section. For the binary logistic regression approach we take the following dichotomous variables.

$\mathrm{Y}=0$ HIV-TB does not usedrugsinjections

$\mathrm{Y}=1 \mathrm{HIV}-\mathrm{TB}$ drugsinjections

Then we obtained the following model.

Table 2: Logistic regression model of the associated factors for HIV TB (IDU)

\begin{tabular}{llccccc}
\hline Dependent Variable & Independent Variable & $\begin{array}{c}\text { Std. } \\
\text { Coefficient } \\
\text { Beta }(\beta)\end{array}$ & S.E & & Adjusted OR & $\begin{array}{c}95 \% \text { C.I. for Adjusted } \\
\text { OR }\end{array}$ \\
& & & & Lower & Upper \\
\hline HIV_TB(IDU) & Age & 0.027 & 0.020 & $1.027^{*}$ & 0.987 & 1.069 \\
& Gender & 1.636 & 0.829 & $5.133^{*}$ & 1.011 & 26.058 \\
& CD4 & 0.570 & 0.376 & $1.768^{*}$ & 0.847 & 3.693 \\
& Heterosexual & 0.655 & 0.551 & $1.926^{*}$ & 0.655 & 5.666 \\
& Smoking & 1.156 & 0.507 & $3.177^{*}$ & 1.175 & 8.587 \\
& Pneumonia & -0.942 & 0.690 & $0.390^{*}$ & 0.101 & 1.508 \\
\hline & Hosmer and Lemeshow Test & \multicolumn{3}{l}{ p-value 0.281 } \\
& Area under the Curve & \multicolumn{3}{c}{$0.731(95 \%$ CI: 0.651, 0.811) } &
\end{tabular}

Based on Table 2, we can make astatement on the occurrence of risk factors HIV_TB(IDU) with respect to the risk. For age, a person aged 33 years and above are with in a 1.027 probability of having HIV-positive incidents with $\mathrm{TB}$ disease among IDUs compared to a younger person $(\mathrm{OR}=1.027,95 \%$ CI: $0.987-1.069$, pvalue $<0.191$ ). Apparently factor for HIV-positive incident TB disease among IDUs are more likely to occur on the men in 5.133 compared with the probability of a woman (OR $=5.133,95 \%$ CI: $1.011-26.058$, p-value $<0.048)$. Factor for CD4, CD4 content level of a person less than $200 / \mathrm{mm} 3(<200 / \mathrm{mm} 3)$ has a probability of 1.768 HIV-positive incidents with TB disease among IDUs (HIV_TB (IDU)) compared to the level of a CD4 content in the body is not less than $200 / \mathrm{mm} 3(\mathrm{OR}=1.768,95 \%$ CI: $0.847-3.693$, p-value $<0.129)$ after adjusting for all factors with other means.

Meanwhile for heterosexual, heterosexual person does have the possibility to experience the 1.926 HIV-positive incident TB disease among IDUs (HIV_TB (IDU)) compared to someone who does not do heterosexuals $(\mathrm{OR}=1.926,95 \% \mathrm{CI}$ : $0.655-5.666, \mathrm{p}$-value $<0.234)$. Factor for smoking, a person who smokes has aprobability of occurring 3.177 HIV-positive incident TB disease among IDUs (HIV_TB (IDU)) compared to someone who does not smoke ( $\mathrm{OR}=3.177,95 \% \mathrm{CI}: 1.175-8.587$, $\mathrm{p}$-value $<0.023)$. The last significant factor 
was pneumonia, a person suffering from pneumonia have occurred 0.390 the probability of HIV-positive incident TB disease among IDUs (HIV TB (IDU)) than someone who not suffering from pneumonia $(\mathrm{OR}=$ $0.390,95 \%$ CI: $0.101-1.508$, p-value $<0.172$ ). Hosmer and Lemeshow Test is based on grouping cases into deciles of risk. It compares the observed probability with the expected probability within each decile. The pvalue is checked. If it is $>0.05$, there is no significant difference between the observed probability and the expected probability. Based on the Table 2 above, $p$-value $=0.281$ obtain greater than 0.05 ( $p$-value $>0.05)$ and suggesting that the model was fitted to the data well.

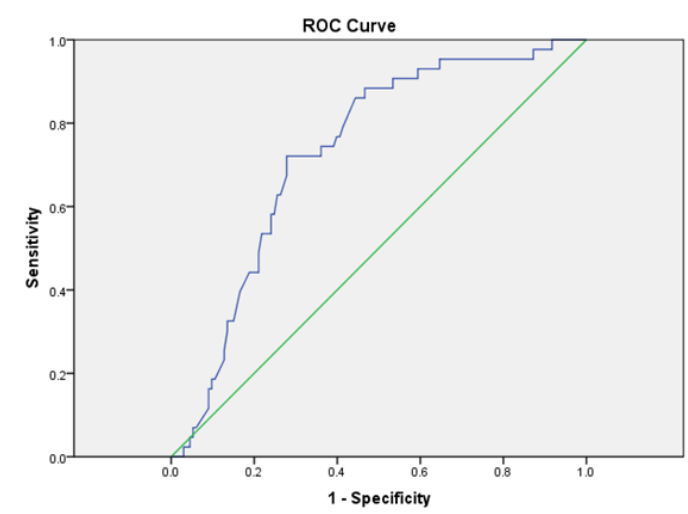

Figure 1: ROC Curve

The ROC curve is a fundamental tool for diagnostic test evaluation. It's a graphical plot of the sensitivity which measure of the overall performance of a diagnostic test. ROC Curve take on any value between 0 and 1 , since both the $x$ and $y$ axes have values ranging from 0 to 1 . If the area is 1.0 , we have an ideal test, because it achieves both $100 \%$ sensitivity and $100 \%$ specificity. If the area is 0.5 , then we have a test which has effectively $50 \%$ sensitivity and $50 \%$ specificity [18]. In practice, a diagnostic test is going to have an area somewhere between these two extremes. Area under the ROC curve is 0.731 (95\% CI: $0.651,0.811)$. It is significantly different from 0.05 (0.000). The model can accurately discriminate $73.1 \%$ of the cases.

Table 3: Risk Estimate

\begin{tabular}{|c|c|c|c|}
\hline Dependent Variable & Independent Variable & Odds Ratio (OR) & $\begin{array}{c}\text { Pearson's chi-squared } \\
\text { ( } \rho \text {-value })\end{array}$ \\
\hline \multirow{12}{*}{$\begin{array}{l}(\mathrm{HIV} \text { TB } \\
(+\mathrm{IDU}) /(\mathrm{IDU})\end{array}$} & \multicolumn{3}{|c|}{ Demographic Factor } \\
\hline & Gender & 5.716 & $0.010^{*}$ \\
\hline & Race & 0.823 & 0.727 \\
\hline & \multicolumn{3}{|c|}{ Sosio-demographic Factor } \\
\hline & Smoking & 3.626 & $0.003 *$ \\
\hline & Heterosexual & 0.666 & 0.352 \\
\hline & Receivingblood & 0.768 & 0.815 \\
\hline & \multicolumn{3}{|c|}{ Disease Factor } \\
\hline & Hepatitis & 0.832 & 0.785 \\
\hline & Pneumonia & 0.450 & $0.208^{*}$ \\
\hline & Toxoplasmosis & 0.672 & 0.618 \\
\hline & CD4 $<200$ cells $/ \mathrm{mm} 3$ & 1.861 & $0.080^{*}$ \\
\hline
\end{tabular}

Significant Level, $0.25^{*}$

Based on the probability ratio for gender factor is highest between factors different with the ratio value totaled 5.716. This means, men have a probability of 5.716 times to be infected HIV_TB disease with positive IDU compared negative IDU. The smoker has probability to get the HIV_TB disease with IDU as much as 3.626 times compared HIV_TB disease not IDU. CD4 count that less from 200 cells / mm 3 are factors which contribute to HIV_TB disease with positive IDU. The ratio value achieved totalled 1.861 and can be concluded that a person who contain CD4 cell that less from 200 cells / mm3 (body immunity system) have 1.861 chances get a HIV_TB disease with IDU. For someone who infected pneumonia has 0.45 chances get a HIV_TB disease with IDU. Meanwhile for race, heterosexual, blood recipient, hepatitis and toxoplasmosis is not significant because the p-value greater than 0.25 . So can be concluded that does not exist between relationship these factors on HIV_TB factor with IDU. 


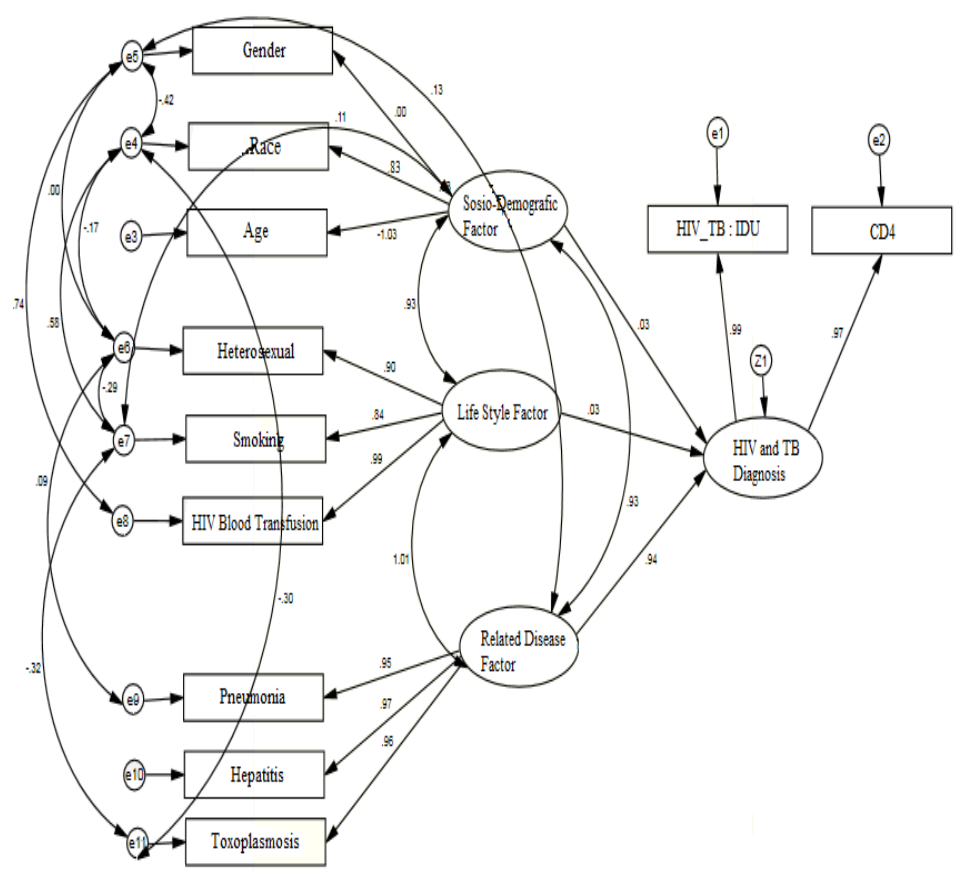

Figure 2: Structural Equation Modeling (SEM)

The maximum likelihood estimation results of the analysis indicate that the critical ratios for the diagnosis of HIV and TB on the two indicator variables are significant at a p-value. The beta coefficient for the variable diagnosis of HIV and TB patients for HIV-TB: IDU was 0.988 (positive relationship). The relationship between these variables is strong. Meanwhile, the beta coefficient for the variable HIV and TB to CD4 was 0.971 (positive relationship).For socio-demographic factors, there are three indicator variables were age, gender and race. Age and race variables are variables that are not significant socio-demographic variables. While, the gender was significant at a p-value less than 0.05 . The beta coefficient for socio-demographic variables of gender was 0.971 . This means that the gender variable is the variable that contributes to social-demographic factors, and the relationship is stronger than age and race variables.

While for lifestyle factors were found three indicator variables, namely smoking, heterosexual and receiving HIV blood. Heterosexual variables, smoking and receiving HIV blood are a significant factor for the latent variables. The beta coefficient for the variable of heterosexual lifestyle was 0.903 (positive relationship), the beta coefficients for lifestyle variables on smoking was 0.835 (positive relationship) and beta coefficients for lifestyle variables on HIV blood recipient was -1.033 (negative relationship). After that for disease factor which related on the other hand have three variables namely pneumonia, hepatitis and toxoplasmosis. All three indicator variables are variable forecaster that is significant for a variable disease which related $\mathrm{p}<0.05$. Coefficient value for variable disease which related on pneumonia is totalled 0.935 , coefficient value for variable disease which related on hepatitis is totalled 0.962 and coefficient value for variable disease which related on toxoplasmosis is totalled 0.962 .

\section{Comparison of logistic regression modeling and structural equation modeling}

Structural equation modeling (SEM) is a second generation data analysis technique [3] that can be used to test the extent of information systems research meet recognized standards for high quality statistical analysis. Unlike the first generation of statistical tools such as Logistic Regression, SEM allows researchers to answer a set of interrelated research questions in a single analysis, a systematic and comprehensive by the relationship between the various models are not independent and dependent constructs simultaneous [1]. Table 4 below is a comparison of the results between the logistic regression analysis with structural equation modeling analysis. 
Table 4: Comparison of logistic regression modeling and structural equation modeling

\begin{tabular}{|c|c|c|}
\hline COMPARISON & LOGISTIC REGRESSION ANALYSIS & $\begin{array}{c}\text { STRUCTURAL EQUATION MODELING } \\
\text { ANALYSIS (SEM) }\end{array}$ \\
\hline Variables & $\begin{array}{l}\text {-Dependent variables } \\
\text { HIV and TB Diagnosis } \\
\text {-Independent variables: } \\
\text { Age }(\beta=0.034, \mathrm{p}-\text { value }=0.136) \\
\text { Gender }(\beta=1.821, \mathrm{p}-\text { value }=0.034) \\
\text { Race }(\beta=0.488, \mathrm{p}-\text { value }=1.629) \\
\text { CD4 }(\beta=0.588, \mathrm{p}-\text { value }=0.123) \\
\text { Heterosexual } \\
(\beta=0.840, \mathrm{p}-\text { value }=0.163) \\
\text { HIV blood } \\
\text { transfusion } \\
(\beta=-0.707, \mathrm{p}-\text { value }=0.557) \\
\text { Smoking }(\beta=1.153, \mathrm{p}-\text { value }=0.025) \\
\text { Hepatitis }(\beta=-0.377, \mathrm{p}-\text { value }=0.603) \\
\text { Pneumonia } \\
(\beta=-1.002, \mathrm{p}-\text { value }=0.151) \\
\text { Toxoplasmosis } \\
(\beta=-0.312, \mathrm{p}-\text { value }=0.724)\end{array}$ & $\begin{array}{l}\text {-Latent variables (Factor): } \\
\text { HIV and TB Diagnosis } \\
\text { HIV_TB (IDU) }(\beta=0.988, \mathrm{p}-\text { value }<0.05) \\
\text { and CD4 }(\beta=0.971, \mathrm{p}-\text { value }<0.05) \\
\text { Sosio-demographic factors } \\
\text { Age, Gender }(\beta=0.971, \mathrm{p}-\text { value }<0.05) \text { and } \\
\text { Race }(\beta=0.825, \mathrm{p}-\text { value }<0.05) \\
\text { Life Style factors } \\
\text { Heterosexual }(\beta=0.903, \mathrm{p}-\text { value }<0.05), \mathrm{HIV} \\
\text { blood transfusion } \\
(\beta=-1.033, \mathrm{p}-\text { value }<0.05) \text { and } \\
\text { Smoking }(\beta=0.835, \mathrm{p}-\text { value }<0.05) \\
\text { Related disease factors } \\
\text { Hepatitis }(\beta=0.962, \mathrm{p}-\text { value }<0.05), \\
\text { pneumonia }(\beta=0.953, \mathrm{p}-\text { value }<0.05) \text { and } \\
\text { Toxoplasmosis }(\beta=0.962, \mathrm{p}-\text { value }<0.05) \\
\text {-Relations correlation value observed in the model the } \\
\text { correlation of the Z1, e1 to e11 }\end{array}$ \\
\hline Level of significant & $\begin{array}{l}\text { *Significant level in medical } \\
\text { field, } p<0.25[14]\end{array}$ & *Significant level $\mathrm{p}<0.05$ \\
\hline
\end{tabular}

\section{Summary And Conclusion}

Through binary logistic regression analysis, there are eight of the most significant factors out of ten factors that are tested and identified as having a major influence on HIV-positive patients with TB and IDU were age, gender, level of CD4 cell content of less than 200/mm3, heterosexual, smoking and pneumonia. These factors are selected based on the criteria set out to achieve significant model at $p$-value $<0.25$. According to Martín et.al, 2000 [13], HIV infection and TB (20.1\%) involving IDU is aged between 29.74 .2 years higher than those aged $26.5 \pm 5.3$ years $(<0.001)$. HIV prevalence of smokers is that injection drug users recorded the highest frequency among 25-54 year-old category. Smokers have a higher prevalence among HIV-infected patients with drug injection needle users [4].

Based on the results of structural equation modelling found that there are four measurement models developed from the relationship between latent variables. Latent variable HIV and TB diagnosis associated with two aspects of HIV_TB : IDU and white blood cells. Diagnoses of HIV and TB on both indicator variables are significant at the value $p<0.05$. $\beta$ Coefficient for the variable diagnosis of HIV and TB patients for HIV and TB with IDU was 0.988 . For socio -demographic factors, there are three indicator variables were age, gender and race. Age and race variables are variables that are not significant socio-demographic variables. While the gender variable is significant at $p$-values $<0.05(p<0.000)$. The coefficient for sociodemographic variables of gender was 0.971 . While for lifestyle factors were found three indicator variables, namely smoking, heterosexual and receiving HIV blood. Heterosexual variables, smoking and receiving HIV blood is a significant factor for the latent variable, $p$-value $<0.05$. Next for disease -related factors were found three variables, namely pneumonia, hepatitis and toxoplasmosis. The three indicator variables are a significant predictor variable for related disease variables $p<0.05$.

Comparison between the two models there is a difference in significance level. For logistic regression analysis for age significance value $(p<0.25)$ is different for the relationship between socio-demographic factors and age $(p>0.25)$ is not meaningful. While the significance value of a variable gender, heterosexual, CD4, smoking and pneumonia are significantly different for the two models. The only difference lies in the level of significance for structural equation modeling is more and approaches to value $p=0.000$. 
From the study it can be concluded that the performed logistic regression method is very suitable model in determining the value of the correlation between catalyst factors in a case. Through logistic regression analysis carried out in a study involving HIV-positive TB disease and IDU, there are other benefits that can be obtained through logistic regression. According to Kupek, 2006 [11] Structural Equation Modeling is better than the logistic model because for structural equation modeling it's suggested the influence of the latent variables that may not be detected by logistic regression. However, classification of SEM in general is similar to logistic regression.

In addition, the parties concerned should provide ongoing effort to increase awareness about the dangers of social relations as well as HIV positive with TB and this IDU. Social relationships and adopt a healthy lifestyle factors contribute to the occurrence of HIV-positive TB disease and IDU among our society today. Among the efforts that need to be done to curb the problem is to ensure the health at maximum level and get treatment as early as the time of exposure to HIV. Parents need to play an important role in educating children from another school about the dangers of social relations that can have adverse effects such as HIV disease. Parents should also monitor and control the movement of their children and provide adequate religious education. In this way the problem could stem infection with TB and HIV-positive IDUs from further spreading.

\section{References}

[1]. Anderson, J. C., \& Gerbing, D. W. (1988). Structural equation modeling in practice: A review and recommended two-step approach. Psychological Bulletin, 103 (3), 411-423.

[2]. Babiker, a G., Peto, T., Porter, K., Walker, a S., \& Darbyshire, J. H. (2001). Age as a determinant of survival in HIV infection. Journal of clinical epidemiology, 54 Suppll(July), S16-21. Retrieved from http://www.ncbi.nlm.nih.gov/pubmed/11750205

[3]. Bagozzi, R.P. and Fornell, C. 1982, Theoretical concepts, measurements, and meaning, inFornell, C. (Ed.), A Second Generation of Multivariate Analysis, Vol. 1, Praeger, New York,NY, 24-38.

[4]. Benard, A., Tessier, J., Rambeloarisoa, J., Bonnet, F., Fossoux, H., Neau, D., Dutronc, H., et al. (2006). HIV infection and tobacco smoking behaviour : Prospects for prevention? ANRS CO3 Aquitaine Cohort, 2002. International Journal of Tuberculosis and Lung Disease, 10 (4), 378-383.

[5]. Brassard, P., Bruneau, J., Schwartzman, K.,Sénécal, M., \& Menzies, D. (2004). Yield of tuberculin screening among injection drug users. The international journal of tuberculosis and lung disease: the official journal of the International Union against Tuberculosis and Lung Disease, 8(8), 988-93.

[6]. De Bruyn, M., H. Jackson, M. Wijermars, V. Curtin Knight, and R. Berkvens. 1995. Facing the Challenges of HIV/AIDS/STDs: A Gender-based Response. Royal Tropical Institute,SAfAIDS, and the WHO Global Programme on AIDS.

[7]. Fazidah A Siregar. 2004 Pengenalan dan Pencegahan AIDS. Fakultas Kesehatan Masyarakat Universitas Sumatera Utara.

[8]. Ismail, I., \& Bulgiba, A. (2013). Determinants of unsuccessful tuberculosis treatment outcomes in Malaysian HIV-infected patients.Preventive medicine.doi:10.1016/j.ypmed.2012.12.023

[9]. Keizer, S. T., Langendam, M. M., Van Deutekom, H., Coutinho, R. a, \& Van Ameijden, E. J. (2000). How does tuberculosis relate to HIV positive and HIV negative drug users? Journal of epidemiology and community health,54(1), 64-8. Retrieved from http://www.pubmedcentral.nih.gov/articlerender.fcgi?artid1731536\&tool=pmcentrez\&rendertype=abstract.

[10]. Kumar, S. R., Swaminathan, S., Flanigan, T., Mayer, K. H., \& Niaura, R. (2009). HIV \& smoking in India. The Indian journal of medical research, 130(1), 15-22. Retrieved from http://www.ncbi.nlm.nih.gov/pubmed/19700796

[11]. Kupek, E. (2006). Beyond logistic regression: structural equations modelling for binary variables and its application to investigating unobserved confounders. BMC medical research methodology, 6, 13. doi:10.1186/1471-2288-6-13

[12]. Marco., A., Cayla., J. A., Serrar., M., Pedrc.,Sanrama., Guerrero., R. \& Ribot., N.1998. Predictors of adherence to tuberculosis treatmentin a supervised therapy programme for prisoners before and after release (Study Group ofAdherence to Tuberculosis Treatment in Prisoners). European Respiratory Journal. 12: 967-97

[13]. Martín, V., Caylà, J. a, Bolea, a, \& Castilla, J. (2000). Mycobacterium tuberculosis and human immunodeficiency virus co-infection in intravenous drug users on admission to prison. The international journal of tuberculosis and lung disease: the official journal of the International Union against Tuberculosis and Lung Disease, 4(1), 41-6. Retrieved from http://www.ncbi.nlm.nih.gov/pubmed/10654643

[14]. Mickey, J. and Greenland, S. (1989). "A study of the impact of confounder-selection criteria on effect estimation," American Journal of Epidemiology, 129, 125-137.

[15]. Nissapatorn, V., Lee, C., Fatt, Q. K., \& Abdullah, K. A. (2003). AIDS-related opportunisticinfections in Hospital Kuala Lumpur. Japanese journal of infectious diseases, 56(5-6), 187-92.Retrieved from http://www.ncbi.nlm.nih.gov/pubmed/14695428

[16]. Perelson, a S., Kirschner, D. E., \& De Boer, R. (1993). Dynamics of HIV infection of CD4+ T cells. Mathematical biosciences, 114(1), 81 125. Retrieved from http://www.ncbi.nlm.nih.gov/pubmed/8096155

[17]. Sharifi-Mood B, avi-Naini R, Salehi M, Hashemi M, Rakhshani F. 2006. Spectrum of clinical disease in a series of hospitalized HIV-infected patients from southeast of Iran. Saudi Med J; 27: 1362-66.

[18]. W. M. A. W. Ahmad, N. A. Aleng and Zalila Ali, binary logistic regression analysis technique used in analyzing the categorical data in education science: a case study of Terengganu state,Malaysia. World Appl. Sci. J.,9(9), 2010, 1062-1066. 